WEISSHEIMER, Loreno. Direitos fundamentais, perspectiva histórica, características e função. Revista Eletrônica Direito e Política, Programa de Pós-Graduação Stricto Sensu em Ciência Jurídica da UNIVALI, Itajaí, v.10, n.2, 10 quadrimestre de 2015. Disponível em: www.univali.br/direitoepolitica - ISSN 1980-7791.

\title{
DIREITOS FUNDAMENTAIS, PERSPECTIVA HISTÓRICA, CARACTERÍSTICAS E FUNÇÃO
}

\author{
FUNDAMENTAL RIGHTS, HISTORICAL PERSPECTIVE, FEATURES AND \\ FUNCTION
}

Loreno Weissheimer ${ }^{1}$

SUMÁRIO: Introdução; 1. Direitos fundamentais; 2. Evolução histórica dos direitos fundamentais; 3 . Características dos direitos fundamentais 4 . Função dos direitos fundamentais; Considerações finais; Referências das fontes citadas.

RESUMO: O presente artigo se propõe ao estudo dos Direitos Fundamentais, sua evolução histórica, seu processo de formação ideal, bem como demonstrar a formação do seu conceito. Demonstrar o tratamento dado aos dos Direitos Fundamentais no Brasil e apresentar um estudo de suas características, tais como: indisponibilidade e inalienabilidade, a constitucionalização, vinculação dos Poderes Públicos e as funções: de defesa, de prestação social e de nãodiscriminação. Quanto à metodologia, o relato dos resultados será composto na base lógica Indutiva. Nas diversas fases da Pesquisa, serão utilizadas as Técnicas do Referente, da Categoria, do Conceito Operacional e da Pesquisa Bibliográfica.

Palavras-Chave: Estado; Constituição; Direitos Humanos; Direitos Fundamentais; Dignidade da Pessoa Humana.

ABSTRACT: This article proposes the study of Fundamental Rights, its historical evolution, its ideal training process and demonstrate the formation of the concept. Demonstrate the treatment of Fundamental Rights in Brazil and present a study of its features such as: unavailability and alienation, constitutionalization, linking public authorities and functions: defense, social benefit and nondiscrimination. Regarding the methodology, the reporting of results will consist in

\footnotetext{
1 Mestrando em Ciência Jurídica na Universidade do Vale do Itajaí (UNIVALI). Especialista em Direito Tributário pela UFSC. Graduado pela Pontifícia Universidade Católica do Rio Grande do Sul (PUC/RS). Procurador do Estado de Santa Catarina. Florianópolis - Santa Catarina, Brasil. loreno@pge.sc.gov.br.
} 
WEISSHEIMER, Loreno. Direitos fundamentais, perspectiva histórica, características e função. Revista Eletrônica Direito e Política, Programa de Pós-Graduação Stricto Sensu em Ciência Jurídica da UNIVALI, Itajaí, v.10, n.2, $1^{0}$ quadrimestre de 2015. Disponível em: www.univali.br/direitoepolitica - ISSN 1980-7791.

Inductive rationale. In the various stages of the search, the Techniques Concerning will be used, the category of the Operational Concept and Library Research.

Keywords: State; Constitution; Human Rights; Fundamental Rights; Human Dignity.

\section{INTRODUÇÃO}

Os Direitos Fundamentais tem merecido título próprio nas constituições dos estados modernos, Esse fato tem ensejado seu estudo sob variados aspectos, nesse contexto o presente artigo tem a finalidade de trazer um estudo dos aspectos do processo histórico de sua formação, seu tratamento no Brasil, assim como analisar suas características e função. O primeiro capítulo trará o seu desenvolvimento histórico, o uso das diversas denominações, como: direitos naturais, direitos públicos subjetivos, liberdades públicas, direitos morais, direitos dos povos, direitos humanos e direitos fundamentais. No segundo se tratará da evolução histórica dos Direitos Fundamentais, com o surgimento do estado nacional moderno, assim como das influências das Revoluções Inglesa, Americana e Francesa e a Declaração Universal dos Direitos do Homem e do Cidadão pela Assembleia Geral das Nações Unidas de dezembro de 1948,como o tratamento dado aos Direitos Fundamentais no Brasil. No capítulo terceiro passa a se tratar das características dos Direitos Fundamentais (essenciais e ontológicas), tais como: a indisponibilidade e inalienabilidade, a constitucionalização e a vinculação dos Poderes Públicos. No quarto capítulo será tratada a função dos Direitos Fundamentais, como: de defesa, de prestação social e de não-discriminização. Por fim se apresentará uma conclusão.Quanto à metodologia, o relato dos resultados será composto na base lógica Indutiva ${ }^{2}$. Nas

\footnotetext{
2 [...] pesquisar e identificar as partes de um fenômeno e colecioná-las de modo a ter uma percepção ou conclusão geral [...]. (PASOLD, Cesar Luis. Metodologia da pesquisa jurídica: Teoria e prática. 11 ed. Florianópolis: Conceito editorial/Milleniuum, 2008. p. 86).
} 
WEISSHEIMER, Loreno. Direitos fundamentais, perspectiva histórica, características e função. Revista Eletrônica Direito e Política, Programa de Pós-Graduação Stricto Sensu em Ciência Jurídica da UNIVALI, Itajaí, v.10, n.2, $1^{0}$ quadrimestre de 2015. Disponível em: www.univali.br/direitoepolitica - ISSN 1980-7791.

diversas fases da Pesquisa, serão utilizadas as Técnicas do Referente ${ }^{3}$, da Categoria $^{4}$, do Conceito Operacional ${ }^{5}$ e da Pesquisa Bibliográfica ${ }^{6}$.

\section{DIREITOS FUNDAMENTAIS}

A humanidade, no decorrer da história atravessou diversas fases, cada qual com suas particularidades, donde percebe-se que as evoluções políticas, científicas, tecnológicas, sociais, econômicas e jurídicas se apresentam quase sempre lentas e graduais.

Siqueira e Piccirillo aduzem que:

A evolução histórica dos direitos inerentes à pessoa humana também é lenta e gradual. Não são reconhecidos ou construídos todos de uma vez, mas sim conforme a própria experiência da vida humana em sociedade, por isto é de extrema importância, para entender seu significado atual compreender como eles foram observados em eras passadas para eliminar os erros e aperfeiçoar os acertos ${ }^{7}$.

Doutrinariamente debate-se sobre a terminologia mais centrada a mencionar os direitos fundamentais a pessoa humana. Exemplifica-se como sendo: direitos humanos, direitos morais, direitos naturais, direitos públicos subjetivos, direitos dos povos, liberdades públicas, direitos fundamentais, dentre outros.

No tocante a expressão direitos naturais, identifica-se com o jus-naturalismo, são fruto de uma revelação, não consideram a sua construção histórica. Esse

\footnotetext{
3 [...] explicitação prévia do(s) motivo(s), do(s) objetivo(s) e do produto desejado, delimitando o alcance temático e de abordagem para a atividade intelectual, especialmente para uma pesquisa." (PASOLD, Cesar Luis. Metodologia da pesquisa jurídica: Teoria e prática. p. 53).

${ }^{4}[\ldots]$ palavra ou expressão estratégica à elaboração e/ou à expressão de uma ideia." (PASOLD, Cesar Luis. Metodologia da pesquisa jurídica: Teoria e prática. p. 25).

${ }^{5}$ [...] uma definição para uma palavra ou expressão, com o desejo de que tal definição seja aceita para os efeitos das ideias que expomos [...]. (PASOLD, Cesar Luis. Metodologia da pesquisa jurídica: Teoria e prática. p. 37).

${ }^{6}$ Técnica de investigação em livros, repertórios jurisprudenciais e coletâneas legais." (PASOLD, Cesar Luis. Metodologia da pesquisa jurídica: Teoria e prática. p. 209).

7 SIQUEIRA, Dirceu Pereira; PICCIRILLO, Miguel Belinati. Direitos fundamentais: a evolução histórica dos direitos humanos, um longo caminho. Artigo postado em 2012, p.1.
} 
WEISSHEIMER, Loreno. Direitos fundamentais, perspectiva histórica, características e função. Revista Eletrônica Direito e Política, Programa de Pós-Graduação Stricto Sensu em Ciência Jurídica da UNIVALI, Itajaí, v.10, n.2, $1^{\circ}$ quadrimestre de 2015. Disponível em: www.univali.br/direitoepolitica - ISSN 1980-7791.

termo remete a momentos históricos anteriores as primeiras Declarações do Século XVIII, usado para nomear direitos essenciais à pessoa humana. Está em desuso, usado somente para estudo deste período ${ }^{8}$.

A designação como direitos públicos subjetivos surgiu para delimitar os direitos ditos essenciais à pessoa humana dentro de um marco positivista, preso ao conceito de Estado Liberal atuar como um limite ao poder político e não a relações entre particulares, não abrangendo muitas das situações que é mister reivindicar tais direitos ${ }^{9}$.

O termo liberdades públicas utilizado na doutrina francesa, compreende aquelas ligadas ao Estado e aos particulares, sendo públicas porque estão protegidas pelo Direito, mas, não abrange os direitos sociais e econômicos ${ }^{10}$.

A expressão direitos morais foi usado no direito anglo-saxão com conotação jusnaturalista, atrelando-se a um pensamento de Estado Liberal que dificulta os direitos de participação política, sociais, culturais e econômicos ${ }^{11}$.

Segundo Miranda ${ }^{12}$, o termo direitos dos povos é usado para assinalar direitos que os povos "têm de determinar seu destino, no campo político, social, cultural, econômico, o direito de se relacionar com outros Estados, direito a paz, não abrangendo, entretanto os direitos da pessoas como individuais, concretas, insubstituíveis".

\footnotetext{
8 PECES-BARBA, Gregório. Curso de Derechos Fundamentales: teoria general. Madrid: Universidad Carlos III, 1995, p. 35.

${ }^{9}$ LUÑO, Antonio Enrique Pérez. Derechos humanos, estado de derecho y constitucion. 6 . ed. Madrid: Tecnos, 1999.

${ }^{10}$ ISRAEL, Jean-Jacques. Direito das liberdades fundamentais. Barueri: Manole, 2005.

11 PECES-BARBA, Gregório. Curso de Derechos Fundamentales: teoria general. Madrid: Universidad Carlos III, 1995.

${ }^{12}$ MIRANDA, Jorge. Manual de direito constitucional Tomo IV. 3. ed. Coimbra: Coimbra, 2000, p. 68.
} 
WEISSHEIMER, Loreno. Direitos fundamentais, perspectiva histórica, características e função. Revista Eletrônica Direito e Política, Programa de Pós-Graduação Stricto Sensu em Ciência Jurídica da UNIVALI, Itajaí, v.10, n.2, $1^{\circ}$ quadrimestre de 2015. Disponível em: www.univali.br/direitoepolitica - ISSN 1980-7791.

Para Siqueira e Piccirillo ${ }^{13}$, os termos hora descritos restringem o alcance dos direitos essenciais à pessoa humana. Ao se utilizar tais termos, pode-se estar causando prejuízos imensos à proteção e ao reconhecimento de tais direitos.

Ressalta-se que os termos direitos humanos e direitos fundamentais expressam maiores conotações e dão uma maior significação para melhor compreender o tema desta pesquisa. Os direitos humanos são inerentes a própria condição humana; "[...] seu reconhecimento, sua proteção é fruto de todo um processo histórico de luta contra o poder e de busca de um sentido para a humanidade ${ }^{14}$. Já, os direitos fundamentais surgiram, "a partir do processo de positivação dos direitos humanos, a partir do reconhecimento, pelas legislações positivas de direitos considerados inerentes a pessoa humana"15.

Canotilho $^{16}$ caminha na mesma direção quando escreve que "as expressões direitos do homem e direitos fundamentais são frequentemente utilizadas como sinônimas". Para ele, quanto à origem e significado é possível distingui-las como: direitos do homem são direitos válidos para todos os povos, em todos os tempos; já os direitos fundamentais são aqueles direitos jurídicoinstitucionalmente garantidos e limitados no espaço e tempo.

Para Antunes ${ }^{17}$, os direitos humanos podem ser considerados como sendo os direitos que buscam a proteção da pessoa humana "tanto em seu aspecto individual como em seu convívio social, em caráter universal $[\ldots]$, sem o reconhecimento de fronteiras políticas todas decorrentes de conquistas históricas e independentes de positivação em uma ordem específica".

13 SIQUEIRA, Dirceu Pereira; PICCIRILLO, Miguel Belinati. Direitos fundamentais: a evolução histórica dos direitos humanos, um longo caminho. In: Âmbito Jurídico, Rio Grande, XII, n. 61, fev 2009.

14 SIQUEIRA, Dirceu Pereira; PICCIRILLO, Miguel Belinati. Direitos fundamentais: a evolução histórica dos direitos humanos, um longo caminho. In: Âmbito Jurídico, Rio Grande, XII, n. 61, fev 2009, p.5.

15 SIQUEIRA, Dirceu Pereira; PICCIRILLO, Miguel Belinati. Direitos fundamentais: a evolução histórica dos direitos humanos, um longo caminho. In: Âmbito Jurídico, Rio Grande, XII, n. 61, fev. 2009, p.9.

16 CANOTILHO, José Joaquim Gomes.Direito constitucional e teoria da constituição. 3. ed. Coimbra: Almedina, 1998, p. 259.

17 ANTUNES, Ruy Barbedo. Direitos Fundamentais e Direitos Humanos: a questão relacional. Rev. Esc. Direito, Pelotas, v. 6, n. 1, p. 331-356, jan./dez., 2005, p. 340. 
WEISSHEIMER, Loreno. Direitos fundamentais, perspectiva histórica, características e função. Revista Eletrônica Direito e Política, Programa de Pós-Graduação Stricto Sensu em Ciência Jurídica da UNIVALI, Itajaí, v.10, n.2, $1^{0}$ quadrimestre de 2015. Disponível em: www.univali.br/direitoepolitica - ISSN 1980-7791.

A preferência pela expressão "direitos fundamentais" é manifestada por Gregório Peces Barba ${ }^{18}$, pois compreende que traduz tanto a moralidade básica como uma base da legalidade. Explica que tanto pode incluir os pressupostos éticos e morais comprometidos com a dignidade e os objetivos da autonomia moral da pessoa humana quanto significado jurídico que converte os direitos em normas materiais básicas do Ordenamento Jurídico, como instrumentos para que o indivíduo desenvolva todo o seu potencial na sociedade.

Entendiendo con flexibilidad lo anterior, derechos fundamentales puede comprender tanto los presupuestos éticos como los componentes jurídicos, significando la relevancia moral de una idea que compromete la dignidad humana y sus objetivos de autonomía moral, y también la relevancia jurídica que convierte a los derechos en norma básica material deI Ordenarniento, $y$ es instrumento necesario para que el individuo desarrolle en la sociedad todas sus potencialidades. Los derechos fundamentales expresan tanto una moralidad básica como uma juridicidad básica ${ }^{19}$.

Segundo Sarlet ${ }^{20}$, é necessário traçar uma diferenciação entre as expressões: "direitos do homem", "direitos humanos" e "direitos fundamentais", mesmo que seja somente para fins didáticos. Para ele a expressão "direitos do homem" refere-se aos direitos naturais não positivados, ou ainda não positivados; "direitos humanos" refere-se àqueles positivados na esfera do direito internacional e os "direitos fundamentais" fazem referência aos direitos reconhecidos, outorgados e protegidos pelo direito constitucional interno de cada Estado.

\footnotetext{
18 PECES-BARBA, Gregório. Curso de Derechos Fundamentales: teoria general. Madrid: Universidad Carlos III, 1995, p. 37.

19 PECES-BARBA, Gregório. Curso de Derechos Fundamentales: teoria general. Madrid: Universidad Carlos III, 1995, p. 37. Em tradução livre de Loreno Weissheimer: "Compreendendo com flexibilidade as formas anteriores, os direitos fundamentais podem incluir tanto os pressupostos éticos como os componentes jurídicos, ou seja, o significado moral de uma idéia que comprometida com a dignidade humana e os objetivos da autonomia moral do ser humano, e o significado jurídico que converte os direitos em normas materiais básicos do Ordenamento Jurídico, e é uma ferramenta necessária para o indivíduo desenvolva na sociedade todo o seu potencial. Os direitos fundamentais expressam tanto a moralidade básica como uma base da legalidade".
}

20 SARLET, Ingo Wolfgang. A eficácia dos direitos fundamentais. 6. ed. rev. atual. Porto Alegre: Livraria do Advogado, 2006, p.36. 
WEISSHEIMER, Loreno. Direitos fundamentais, perspectiva histórica, características e função. Revista Eletrônica Direito e Política, Programa de Pós-Graduação Stricto Sensu em Ciência Jurídica da UNIVALI, Itajaí, v.10, n.2, $1^{\circ}$ quadrimestre de 2015. Disponível em: www.univali.br/direitoepolitica - ISSN 1980-7791.

\section{EVOLUÇÃO HISTÓRICA DOS DIREITOS FUNDAMENTAIS}

\subsection{Direito Fundamentais na Idade Moderna}

Fatores como o desenvolvimento do comercio, que gerou a classe burguesa; o Estado Moderno, que centralizou o poder político (direitos iguais para todos); a mudança de pensamentos, onde os fenômenos explicam-se cientificamente (razão e não visão religiosa), advindo da globalização da cultura, culmina em uma mudança comportamental ${ }^{21}$.

Nesse sentido, o Estado Moderno surge atrelado à nova classe burguesa, que carecia em sua origem "de um poder absoluto, único, para poder desenvolver sua atividade com segurança, eliminando pouco a pouco a sociedade estamental, para uma nova sociedade onde o indivíduo começará a ter preferência sobre o grupo" 22 .

Conforme Marcos Leite Garcia ${ }^{23}$, a mentalidade individualista é favorecida diante da visão do homem em estamentos, com o amadurecimento do capitalismo resultado da profunda mudança econômica, protagonizado pela burguesia.

Ressaltam-se ainda como destaque: a Reforma Protestante que contrapôs-se a uniformidade da Igreja Católica, dando como importante interpretar pessoalmente as Escrituras Sagradas, através da razão; o Edito de Nantes onde o Rei Enrique IV da França proclamou a liberdade religiosa; o Petition of Rights, de 1628, que reclama a necessidade de consentimento na tributação, o julgamento pelos pares para a privação da liberdade e a proibição de detenções

21 PECES-BARBA, Gregório. Curso de Derechos Fundamentales: teoria general. Madrid: Universidad Carlos III, 1995, p. 37

22 SIQUEIRA, Dirceu Pereira; PICCIRILLO, Miguel Belinati. Direitos fundamentais: a evolução histórica dos direitos humanos, um longo caminho. In: Âmbito Jurídico, Rio Grande, XII, n. 61, fev 2009, p.10.

${ }^{23}$ GARCIA, Marcos Leite. A Contribuição de Christian Thomasius ao Processo de Formação do Ideal dos Direitos Fundamentais. In: Novos Estudos Jurídicos - v. 10 - n. ${ }^{\circ} 2$ - p. 417 jul/dez - 2005, 421. 
WEISSHEIMER, Loreno. Direitos fundamentais, perspectiva histórica, características e função. Revista Eletrônica Direito e Política, Programa de Pós-Graduação Stricto Sensu em Ciência Jurídica da UNIVALI, Itajaí, v.10, n.2, $1^{\circ}$ quadrimestre de 2015. Disponível em: www.univali.br/direitoepolitica - ISSN 1980-7791.

arbitrárias; a Lei de habeas corpus,de 1679 que protegia a liberdade de locomoção ${ }^{24}$.

Mesmo ocorrendo enormes avanços à época, não se pode arrazoar ainda em direitos considerados universais, "pois os direitos eram meras concessões reais podendo ser revogadas, ou seja, não constituíam um limite permanente na atuação do poder político" 25 .

Conforme Maia:

As primeiras normas sobre os direitos humanos surgiram efetivamente no mundo jurídico em 1215, com a Magna Carta inglesa do Rei João-Sem-Terra, mas foi com a Declaração americana de Virgínia, em 1776, e com a Declaração francesa dos Direitos do Homem e do Cidadão, em 1789, que esses direitos ganharam impulso, a serem perseguidos por todos os povos. No entanto, a consolidação dos direitos humanos ocorre com a Declaração Universal dos Direitos Humanos, promulgada pela Assembleia Geral da Organização das Nações Unidas (ONU), através da Resolução 217 A (III), no dia 10 de dezembro de $1948^{26}$.

No campo político, a importância do surgimento do Estado como forma de poder racional e burocratizado, seu crescente poder como Estado absoluto e a utilização do Direito como instrumentum regni, exigirão garantias ao indivíduo, para lhe garantir um espaço pessoal, e a reclamação de uns direitos., destaca Garcia:

No campo político, o pluralismo do poder será substituído pelo Estado como forma de poder racional centralizado e burocratizado. O Estado é soberano, na construção doutrinal que se inicia com Jean Bondin, ou seja, o Estado não reconhece superior e tem o monopólio no uso da força legítima. Seu crescente poder como Estado absoluto e a

24 SIQUEIRA, Dirceu Pereira; PICCIRILLO, Miguel Belinati. Direitos fundamentais: a evolução histórica dos direitos humanos, um longo caminho. In: Âmbito Jurídico, Rio Grande, XII, n. 61, fev 2009, p.5.

25 SIQUEIRA, Dirceu Pereira; PICCIRILLO, Miguel Belinati. Direitos fundamentais: a evolução histórica dos direitos humanos, um longo caminho. In: Âmbito Jurídico, Rio Grande, XII, n. 61, fev 2009, p.11.

26 MAIA, Bruna Michelle Pereira. Tratados internacionais de direitos humanos no ordenamento jurídico brasileiro. 2014. 36f. Trabalho de Conclusão de Curso de Direito da Faculdade de Ciências Jurídicas da Universidade Tuiuti do Paraná. Curitiba. 2014, p. 19. 
WEISSHEIMER, Loreno. Direitos fundamentais, perspectiva histórica, características e função. Revista Eletrônica Direito e Política, Programa de Pós-Graduação Stricto Sensu em Ciência Jurídica da UNIVALI, Itajaí, v.10, n.2, $1^{\circ}$ quadrimestre de 2015. Disponível em: www.univali.br/direitoepolitica - ISSN 1980-7791.

utilização do Direito como instrumenti regni exigirão como antítese, para garantir ao indivíduo um espaço pessoal, a reclamação de uns direitos ${ }^{27}$.

\subsection{As Revoluções Inglesa, Americana e Francesa}

Como contribuição Inglesa, o Bill of Rights de 1689, reconheceu o direito de liberdade, o direito a segurança e o direito a propriedade privada, que mesmo consagrados em outros documentos, eram constantemente violados pelo poder real. Deslocou para o Parlamento a alçada de legislar e criar tributos, institucionalizou a separação de poderes, eliminou o Absolutismo. Contudo, impôs uma religião oficial ${ }^{28}$.

Comparato aduz que:

A Revolução Inglesa apresenta, assim, um caráter contraditório no tocante as liberdades públicas. Se, de um lado, foi estabelecida pela primeira vez no Estado moderno a separação de poderes como garantia das liberdades civis, por outro lado essa fórmula de organização estatal, no Bill of Rights, constituiu o instrumento político de imposição, a todos os súditos do rei da Inglaterra, de uma religião oficial $^{29}$.

A luta americana no intento de consolidar os direitos humanos, pode-se elencar as seguintes passagens: em 1765, colonos tentaram impugnar várias imposições fiscais impostas pela metrópole, reivindicando o mesmo direito que os súditos da matriz. Em 1773, em Boston, 300 pessoas lançaram ao mar caixas com chá, protestando contra impostos advindos da Coroa britânica sobre produtos nativos. Em 1774 criou-se um exército comum entre as colônias abrindo caminho para a Independência. Em 1776 é elaborada a Declaração de Direitos do Bom Povo da Virgínia em que todos os seres humanos são livres e independentes, com direito

27 GARCIA, Marcos Leite. A Contribuição de Christian Thomasius ao Processo de Formação do Ideal dos Direitos Fundamentais. Novos Estudos Jurídicos - v. 10 - n. ${ }^{\circ} 2$ - p. 417 jul/dez - 2005, 421.

28 SIQUEIRA, Dirceu Pereira; PICCIRILLO, Miguel Belinati. Direitos fundamentais: a evolução histórica dos direitos humanos, um longo caminho. In: Âmbito Jurídico, Rio Grande, XII, n. 61, fev 2009, p.11.

${ }^{29}$ COMPARATO, Fábio Konder. A afirmação histórica dos direitos humanos. 3. ed. São Paulo: Saraiva, 2003, p. 92. 
WEISSHEIMER, Loreno. Direitos fundamentais, perspectiva histórica, características e função. Revista Eletrônica Direito e Política, Programa de Pós-Graduação Stricto Sensu em Ciência Jurídica da UNIVALI, Itajaí, v.10, n.2, $1^{\circ}$ quadrimestre de 2015. Disponível em: www.univali.br/direitoepolitica - ISSN 1980-7791.

a vida, a liberdade, a propriedade, a felicidade e a segurança. Em 1776 é elaborada a Declaração de Independência dos Estados Unidos, ressaltando que todos os homens são iguais perante Deus. Em 1789 surge a Declaração dos Direitos do Homem e do Cidadão, que "[...] afirma solenemente que qualquer sociedade em que não esteja assegurada a garantia dos direitos fundamentais nem estabelecida a separação dos poderes não tem constituição"30.

Comparando a Declaração Francesa com as americanas, Fioravanti, assevera que:

[...] la revolución francesa confía los derechos y libertades a la obra de un legislador virtuoso, que es tal porque es altamente representativo del pueblo o nación, más allá de las facciones o de los intereses particulares; mientras que la revolución america desconfía de las virtudes de todo legislador - también del elegido democráticamente [...] y, así, confía los derechos y libertades a la constitución, es decir, a la posibilidad de limitar al legislador con una norma de orden superior ${ }^{31}$.

Embora com diferenças, a Declaração Francesa, as americanas e o Bill of Rights inglês contribuíram para o surgimento do Estado de Direito e com a constitucionalização dos direitos inerentes à pessoa humana. A partir desses acontecimentos históricos, os direitos fundamentais granjearam significação na esfera internacional e no ordenamento jurídico interno de cada Estado. O caminho foi longo e árduo. Não se alcançou ainda, até o momento atual, o cenário almejado, tendo-se muito há se fazer para efetivar os direitos fundamentais ${ }^{32}$.

30 SIQUEIRA, Dirceu Pereira; PICCIRILLO, Miguel Belinati. Direitos fundamentais: a evolução histórica dos direitos humanos, um longo caminho. In: Âmbito Jurídico, Rio Grande, XII, n. 61, fev 2009, p.13.

31 FIORAVANTI, Maurizio. Los derechos fundamentales. 4. ed. Madrid: Trotta, 2003, p. 83. Tradução livre de Loreno Weissheimer: "a revolução francesa confia os direitos e liberdades à obra de um legislador virtuoso, que é tal, porque é altamente representativo do povo ou nação, mas além das facções ou interesses individuais; enquanto a Revolução Americana desconfia das virtudes de todos os legisladores - também o democraticamente eleito [...] e, portanto, confia os direitos e liberdades à Constituição, ou seja, a possibilidade de limitar o legislador com uma norma de ordem superior".

32 SIQUEIRA, Dirceu Pereira; PICCIRILLO, Miguel Belinati. Direitos fundamentais: a evolução histórica dos direitos humanos, um longo caminho. In: Âmbito Jurídico, Rio Grande, XII, n. 61, fev 2009, p.13 
WEISSHEIMER, Loreno. Direitos fundamentais, perspectiva histórica, características e função. Revista Eletrônica Direito e Política, Programa de Pós-Graduação Stricto Sensu em Ciência Jurídica da UNIVALI, Itajaí, v.10, n.2, $1^{\circ}$ quadrimestre de 2015. Disponível em: www.univali.br/direitoepolitica - ISSN 1980-7791.

A Declaração Universal dos Direitos Humanos, de 10 de dezembro de 1948, aprovada pela Assembléia Geral das Nações Unidas, em Paris, enseja o respeito à dignidade de todos os membros da família humana e a igualdade de seus direitos inalienáveis, fundamentando a liberdade, a justiça e a paz no mundo ${ }^{33}$.

Conforme Jo, a Declaração Universal dos Direitos Humanos de 1948:

[...] reconhece como comum a todas as Constituições nacionais o direito político, econômico e social dos indivíduos. Entende-se a característica legal dessa Declaração por disposições de princípios, e não disposições de aplicações. Entretanto, a Declaração torna-se cada vez mais apoiada em regras do costume internacional, sendo citada em várias ocasiões ${ }^{34}$.

Sobre a mesma, Piovesan aduz que:

[...] se caracteriza, primeiramente, por sua amplitude. Compreende um conjunto de direitos e faculdades sem as quais um ser humano não pode desenvolver sua personalidade física, moral e intelectual. Sua segunda característica é a universalidade: é aplicável a todas as pessoas de todos os países, raças, religiões e sexos, seja qual for o regime político dos territórios nos quais incide. [...] objetiva delinear uma ordem pública mundial fundada no respeito à dignidade humana, ao consagrar valores básicos universais ${ }^{35}$.

Para Amaral os direitos humanos foram classificados em três gerações, quais sejam:

(I) os direitos de primeira geração (arts. $4^{\circ}$ a $21^{\circ}$ ) correspondem aos direitos civis e políticos, assim como os direitos fundamentais à vida, à liberdade, não-escravidão, etc. De acordo com esses direitos, é proibida a tortura, bem como as penas degradantes e indignas; (II) os direitos de segunda geração (arts. 22 a 27) englobam os direitos econômicos, sociais e culturais; e (III) os direitos de terceira

33 MAIA, Bruna Michelle Pereira. Tratados internacionais de direitos humanos no ordenamento jurídico brasileiro. 2014. 36f. Trabalho de Conclusão de Curso de Direito da Faculdade de Ciências Jurídicas da Universidade Tuiuti do Paraná. Curitiba. 2014, p. 19.

34 JO, Hee Moon. Introdução ao direito internacional. 2. ed. São Paulo: LTr, 2004, 235.

35 PIOVESAN, Flávia. Direitos humanos e o direito constitucional internacional. São Paulo: Max Limonad, 2002, p. 145-146. 
WEISSHEIMER, Loreno. Direitos fundamentais, perspectiva histórica, características e função. Revista Eletrônica Direito e Política, Programa de Pós-Graduação Stricto Sensu em Ciência Jurídica da UNIVALI, Itajaí, v.10, n.2, $1^{0}$ quadrimestre de 2015. Disponível em: www.univali.br/direitoepolitica - ISSN 1980-7791.

geração contemplam os direitos difusos à paz, ao meio ambiente saudável, à preservação do patrimônio comum da humanidade, etc. ${ }^{36}$.

Segundo D'Angelis" ${ }^{37}$, as gerações de direitos humanos tratam de "uma metodologia para facilitar a compreensão progressiva dos direitos humanos, mas jamais de sua divisão em categorias, pois os direitos humanos representam a somatória de todas essas fases".

\subsection{Direitos Fundamentais no Brasil}

A política brasileira de direitos humanos teve avanços com a Constituição Federal de 1988, que consagrou os princípios da prevalência dos Direitos Humanos e da dignidade da pessoa humana ${ }^{38}$. "O fim da Guerra Fria possibilitou a criação de um novo cenário para a efetivação e, afirmação dos Direitos Humanos"39.

De forma inovadora no constitucionalismo brasileiro a dignidade da pessoa humana foi inserida na constituição de 1988 no "Título I - Dos Princípios Fundamentais" como um dos fundamentos da República (art. 1. , inciso III).

Não se trata de uma criação constitucional, pois a dignidade da pessoa humana é preexistente, trata-se de um conceito a priori, um dado especulativo, tal como a própria pessoa humana. A Constituição declarou a dignidade da pessoa humana como um dos fundamentos da República Federativa do Brasil constituída em Estado Democrático de Direito, reconhecendo a sua existência e a sua eminência, como um valor máximo da ordem jurídica, conforme lição de José Afonso:

\footnotetext{
${ }^{36}$ AMARAL, Renata Campetti. O direito internacional: público e privado. 4. ed. Porto Alegre: Verbo Jurídico, 2008, p. 56.

37 D'ANGELIS, Wagner Rocha, (Org.). Direito internacional do século XXI: integração, justiça e paz. Curitiba: Juruá, 2007. p. 48.

38 PIOVESAN, Flávia. Direitos humanos e o direito constitucional internacional. 14. ed. São Paulo: Saraiva, 2013, p. 371.

39 PIOVESAN, Flávia. Direitos humanos e o direito constitucional internacional. 14. ed. São Paulo: Saraiva, 2013, p. 371.
} 
WEISSHEIMER, Loreno. Direitos fundamentais, perspectiva histórica, características e função. Revista Eletrônica Direito e Política, Programa de Pós-Graduação Stricto Sensu em Ciência Jurídica da UNIVALI, Itajaí, v.10, n.2, $1^{\circ}$ quadrimestre de 2015. Disponível em: www.univali.br/direitoepolitica - ISSN 1980-7791.

Portanto a dignidade da pessoa humana não é uma criação constitucional, pois ela é um desses conceitos a priori, um dado preexistente a toda experiência especulativa, tal como a própria pessoa humana. A Constituição, reconhecendo a sua existência e a sua eminência, transformou-a num valor supremo da ordem jurídica, quando a declara como um dos fundamentos da República Federativa do Brasil constituída em Estado Democrático de Direito ${ }^{40}$.

Ademais, a dignidade da pessoa humana encontra previsão expressa também em outros capítulos da constituição brasileira, veja-se: (artigo 170, caput), quando estabelece que a ordem econômica tem por finalidade assegurar a todos uma existência digna; (artigo 226, $\S 6 .^{\circ}$ ) quando prevê o planejamento familiar nos princípios da dignidade da pessoa humana e da paternidade responsável; (artigo 22, caput), ao assegurar à criança e ao adolescente o direito à dignidade e no artigo 230, ao estabelecer que: "a família, a sociedade e o Estado têm o dever de amparar as pessoas idosas, assegurando sua participação na comunidade, defendendo sua dignidade e bem-estar e garantindo-Ihes o direito à vida".

Para Cármen Antunes da Rocha, a dignidade humana acentua-se como um valor supremo, no qual se contém mesmo a essência do direito que se proteja e se elabora a partir de então:

passa a ser [...] encarecida sobre qualquer outra idéia a embasar as formulações jurídicas do pós-guerra e acentua-se como valor supremo, no qual se contém mesmo a essência do direito que se proteja e se elabora a partir de então ${ }^{41}$.

A mesma autora ainda acentua que a dignidade humana é o limite positivo e negativo de atuação do Estado e das autoridades que o representam e a base de todas as definições e de todos os caminhos interpretativos dos direitos fundamentais:

40 SILVA, José Afonso da: A Dignidade da Pessoa Humana como Valor Supremo da Democracia, in: Revista de Direito Administrativo, vol. 212, 1998, (p. 125-145), p. 91.

${ }^{41}$ ROCHA, Cármen Lúcia Antunes da. O Princípio da dignidade da pessoa humana e a exclusão social. Revista do Instituto Brasileiro de Direitos Humanos, Fortaleza, 2001, p. 53 apud WEYNE, Bruno Cunha. O Princípio da Dignidade Humana, Reflexões a partir da filosofia de Kant, Editora Saraiva, São Paulo, 2013. 
WEISSHEIMER, Loreno. Direitos fundamentais, perspectiva histórica, características e função. Revista Eletrônica Direito e Política, Programa de Pós-Graduação Stricto Sensu em Ciência Jurídica da UNIVALI, Itajaí, v.10, n.2, $1^{0}$ quadrimestre de 2015. Disponível em: www.univali.br/direitoepolitica - ISSN 1980-7791.

limite positivo e negativo de atuação do Estado e das autoridades que o representam passou a ser [...] exatamente o da dignidade humana, base de todas as definições e de todos os caminhos interpretativos dos direitos fundamentais ${ }^{42}$.

Para Barroso, a dignidade humana, como valor fundamental, é também um princípio constitucional, que funciona tanto como justificação moral quanto como fundamento jurídico-normativo dos direitos fundamentais:

Como um valor fundamental que é também um princípio constitucional, a dignidade humana funciona tanto como justificação moral quanto como fundamento jurídico-normativo dos direitos fundamentais ${ }^{43}$.

O termo "direitos humanos", para Sarlet, revelou-se como sendo:

[...] conceito de contornos mais amplos e imprecisos que a noção de direitos fundamentais, de tal sorte que estes possuem sentido mais preciso e restrito, na medida em que constituem o conjunto de direitos e liberdades institucionalmente reconhecidos e garantidos pelo direito positivo de determinado Estado, tratando-se, portanto, de direitos delimitados espacial e temporalmente, cuja denominação se deve ao seu caráter básico e fundamentador do sistema jurídico do Estado de Direito ${ }^{44}$.

Os "direitos humanos" são direitos reconhecidos e positivados por Constituição, que asseguram os direitos de cada cidadão a ter uma vida mais digna, ou seja, "trata-se de situações jurídicas sem as quais a pessoa humana não se realiza, não convive e, às vezes, nem mesmo sobrevive" ${ }^{\prime 45}$.

Canotilho, apresenta as seguintes distinções:

42 ROCHA, Cármen Lúcia Antunes da. O Princípio da dignidade da pessoa humana e a exclusão social. Revista do Instituto Brasileiro de Direitos Humanos, Fortaleza, 2001, p. 53 apud WEYNE, Bruno Cunha. O Princípio da Dignidade Humana, Reflexões a partir da filosofia de Kant, Editora Saraiva, São Paulo, 2013, p.92.

43 BARROSO, Luís Roberto. A Dignidade da Pessoa Humana no Direito Constitucional Contemporâneo, A Construção de um Conceito Jurídico à Luz da Jurisprudência Mundial, editora Fórum, 2. a reimpressão, Belo Horizonte, 2013, p. 64

${ }^{44}$ SARLET, Ingo Wolfgang.A eficácia dos direitos fundamentais. 6 ed. Porto Alegre: Livraria do Advogado, 2006, p. 33.

${ }^{45}$ SILVA, José Afonso da. Curso de Direito Constitucional Positivo. 32a.ed, Malheiros, São Paulo: 2009, p. 178. 
WEISSHEIMER, Loreno. Direitos fundamentais, perspectiva histórica, características e função. Revista Eletrônica Direito e Política, Programa de Pós-Graduação Stricto Sensu em Ciência Jurídica da UNIVALI, Itajaí, v.10, n.2, $1^{0}$ quadrimestre de 2015. Disponível em: www.univali.br/direitoepolitica - ISSN 1980-7791.

Segundo a sua origem e significado poderíamos distinguí-las da seguinte maneira: direitos do homem são direitos válidos para todos os povos e em todos os tempos (dimensão jusnaturalista-universalista); direitos fundamentais são os direitos do homem, jurídico-institucionalmente garantidos e limitados espacio-temporalmente. Os direitos do homem arrancariam da própria natureza humana e daí o seu caráter inviolável, intemporal e universal; os direitos fundamentais seriam os direitos objectivamente vigentes numa ordem jurídica concreta ${ }^{46}$.

Entendendo que os "direitos fundamentais", compreendem um enunciado para a humanidade, positivados em um ordenamento jurídico e, limitados pela geografia e cultura de um povo, Sarlet assevera que:

[...] o termo direitos fundamentais se aplica para aqueles direitos do ser humano reconhecidos e positivados na esfera do direito constitucional positivo de determinado Estado, ao passo que a expressão direitos humanos guardaria relação com os documentos de direito internacional, por referir-se àquelas posições jurídicas que se reconhecem ao ser humano como tal, independentemente de sua vinculação com determinada ordem constitucional, e que, portanto aspiram à validade universal, para todos os povos e tempos, de tal sorte que revelam um inequívoca caráter supranacional ${ }^{47}$.

\section{CARACTERÍSTICAS DOS DIREITOS FUNDAMETAIS}

A significação dos direitos fundamentais e o seu conteúdo concreto, conforme Konrad Hesse ${ }^{48}$, dependem de diversos fatores extrajurídicos, especialmente das peculiaridades, da cultura e da história dos povos

Mesmo sendo, os Direitos Fundamentais um conjunto resultante de todo um contexto histórico-cultural específico de cada sociedade, pode-se apontar

${ }^{46}$ CANOTILHO, José Joaquim Gomes. Direito constitucional e teoria da constituição. 3. ed. Coimbra: Almedina, 1998, p. 391.

${ }^{47}$ SARLET, Ingo Wolfgang. A eficácia dos direitos fundamentais. 6 ed. Porto Alegre: Livraria do Advogado, 2006, p. 35.

48 Konrad Hesse, Apud. BRANCO, Paulo Gustavo Gonet. Aspectos de teoria geral dos direitos fundamentais. In: MENDES, Gilmar Ferreira et al. Hermenêutica e direitos fundamentais. Brasília: Brasília Jurídica, 2002, p. 119. 
WEISSHEIMER, Loreno. Direitos fundamentais, perspectiva histórica, características e função. Revista Eletrônica Direito e Política, Programa de Pós-Graduação Stricto Sensu em Ciência Jurídica da UNIVALI, Itajaí, v.10, n.2, $1^{\circ}$ quadrimestre de 2015. Disponível em: www.univali.br/direitoepolitica - ISSN 1980-7791.

diversas características essenciais e ontológicas que lhes são associadas com mais frequência.

\subsection{A Indisponibilidade/Inalienalibilidade}

Dentre as características dos direitos fundamentais tem-se a indisponibilidade/inalienabilidade, designando que os direitos fundamentais são insusceptíveis de serem transferidos onerosa ou gratuitamente. Esse caráter não se aplica indistintamente a todos e quaisquer direitos fundamentais. É admissível principalmente aos ligados à própria sobrevivência do indivíduo, assim como a direitos concernentes à liberdade, à saúde, à integridade física entre outros. Ressalta-se que apesar de determinados direitos serem indisponíveis, não quer dizer que não podem ser ocasionais e temporariamente limitados ${ }^{49}$.

Os direitos fundamentais também são inalienáveis. Segundo Branco um bem inalienável não pode:

[...] ser disposto por seu titular, que, de igual maneira, não pode torná-lo impossível de ser exercitado para si mesmo, física ou juridicamente. Essa característica explicita que a preterição de um direito fundamental não pode sempre ser justificada pelo mero consentimento por parte do titular desse direito ${ }^{50}$.

Deve-se entender a inalienabilidade como relativa, como por exemplo:

[...] seriam absolutamente nulos, por ilicitude de objeto, contratos que previssem a esterilização voluntária irreversível, a despeito de tratarem de uma prática lícita, plenamente possível em nosso país. Tornar o corpo infértil não é ofensa a direito fundamental, e isto quebra a premissa de que estes são inalienáveis, pois, nesse caso, estaria o

49 SANTOS, Fernanda Barbosa dos; MARQUES, Leonardo Augusto Marinho; DUARTE Hugo Garcez. Direitos fundamentais: a busca por sua efetivação. Disponível em: <http://ambitojuridico.com.br/site/index.php?artigo_id=10201\&n_link=revista_artigos_leitura>. Acesso em mar. 2015.

${ }^{50}$ BRANCO, Paulo Gustavo Gonet. Aspectos de teoria geral dos direitos fundamentais. In: MENDES, Gilmar Ferreira et al. Hermenêutica e direitos fundamentais. Brasília: Brasília Jurídica, 2002, p. 123. 
WEISSHEIMER, Loreno. Direitos fundamentais, perspectiva histórica, características e função. Revista Eletrônica Direito e Política, Programa de Pós-Graduação Stricto Sensu em Ciência Jurídica da UNIVALI, Itajaí, v.10, n.2, $1^{\circ}$ quadrimestre de 2015. Disponível em: www.univali.br/direitoepolitica - ISSN 1980-7791.

titular tornando impossível o exercício de seu direito, e nem por isso deixou tal direito de ser fundamental ${ }^{51}$.

Os direitos fundamentais no tocante a serem inalienáveis, segundo Uchôa52, "são os direitos fundamentais associados à vida biológica (sem a qual não poderia haver dignidade humana) e à possibilidade do homem de ser livre e autodeterminar-se".

Advogar a inalienabilidade absoluta de todos os direitos fundamentais seria excessivamente inadequado. Conforme Uchôa:

[...] a liberdade de expressão é por vezes limitada face a obrigação profissional de manter-se o sigilo. Estados estrangeiros e o Brasil, excepcionalmente, têm aceitado flexibilizar direitos trabalhistas como arma para contrapor-se a necessidade de demissão coletiva. O importante, em hipóteses do gênero, é ter em mente que a disponibilidade dos direitos fundamentais sempre deve estar relacionada a uma medida de razoabilidade ${ }^{53}$.

Canotilho ensina que:

[...] embora se admitam limitações voluntárias quanto ao exercício de direitos específicos em certas condições, não é possível a renúncia de todos os direitos fundamentais. Essa autolimitação voluntária, que deve estar sujeita à revogação a todo tempo, há de guardar relação razoável com a finalidade que se tem em vista com a renúncia ${ }^{54}$.

\footnotetext{
${ }^{51}$ BRANCO, Paulo Gustavo Gonet. Aspectos de teoria geral dos direitos fundamentais. In: MENDES, Gilmar Ferreira et al. Hermenêutica e direitos fundamentais. Brasília: Brasília Jurídica, 2002, p. 124.

52 UCHÔA, Marcelo Ribeiro. Direitos fundamentais: noções gerais e resolução de conflitos. 2006. 55f. monografia da Universidade de Fortaleza, Curso de Mestrado em Direito Constitucional. Fortaleza. 2006, 18.

${ }^{53}$ UCHÔA, Marcelo Ribeiro. Direitos fundamentais: noções gerais e resolução de conflitos. 2006. 55f. monografia da Universidade de Fortaleza, Curso de Mestrado em Direito Constitucional. Fortaleza. 2006, 18.

${ }^{54}$ CANOTILHO, José Joaquim Gomes, apud BRANCO, Paulo Gustavo Gonet. Aspectos de teoria geral dos direitos fundamentais. In: MENDES, Gilmar Ferreira et al. Hermenêutica e direitos fundamentais. Brasília: Brasília Jurídica, 2002, p. 125.
} 
WEISSHEIMER, Loreno. Direitos fundamentais, perspectiva histórica, características e função. Revista Eletrônica Direito e Política, Programa de Pós-Graduação Stricto Sensu em Ciência Jurídica da UNIVALI, Itajaí, v.10, n.2, $1^{\circ}$ quadrimestre de 2015. Disponível em: www.univali.br/direitoepolitica - ISSN 1980-7791.

\subsection{A Constitucionalização}

No tocante a característica de constitucionalização, verifica-se que ao constatar a imprescindibilidade dos direitos fundamentais, esses "passaram a necessitar de um suporte normativo capaz de os colocarem nos ápices dos ordenamentos jurídicos, encontrando abrigo nas Constituições dos Estados Modernos" ${ }^{\prime \prime 5}$.

Uma característica genuinamente associada aos direitos fundamentais é a constitucionalização. Esta característica é que, inclusive, os pode distinguir dos direitos ditos humanos. Branco salienta que:

A expressão direitos humanos, ou direitos do homem, é reservada para aquelas reivindicações de perene respeito a certas posições essenciais ao homem. São direitos postulados em bases jusnaturalistas, contam índole filosófica e não possuem como característica básica a positivação numa ordem jurídica particular. [...] Já a locução direitos fundamentais é reservada aos direitos relacionados com posições básicas das pessoas, inscritos em diplomas normativos de cada Estado ${ }^{56}$.

Conforme Uchôa 57 , "a principal e mais importante decorrência da constitucionalização dos direitos fundamentais é o fato de que imperam sobre toda ordem jurídica estatal, devendo, portanto, serem resguardados até mesmo em face do legislador derivado".

A característica da constitucionalização considera o fato de estarem os direitos fundamentais consagrados em princípios da ordem jurídica ${ }^{58}$.

\footnotetext{
55 SANTOS, Fernanda Barbosa dos; MARQUES, Leonardo Augusto Marinho; DUARTE Hugo Garcez. Direitos fundamentais: a busca por sua efetivação. Disponível em: <http://ambitojuridico.com.br/site/index.php?artigo_id=10201\&n_link=revista_artigos_leitura $>$. Acesso em mar. 2015, p 9.

${ }^{56}$ BRANCO, Paulo Gustavo Gonet. Aspectos de teoria geral dos direitos fundamentais. In: MENDES, Gilmar Ferreira et al. Hermenêutica e direitos fundamentais. Brasília: Brasília Jurídica, 2002, p. 125.

57 UCHÔA, Marcelo Ribeiro. Direitos fundamentais: noções gerais e resolução de conflitos. 2006. 55f. monografia da Universidade de Fortaleza, Curso de Mestrado em Direito Constitucional. Fortaleza. 2006, 18.

${ }^{58}$ BRANCO, Paulo Gustavo Gonet. Aspectos de teoria geral dos direitos fundamentais. In: MENDES, Gilmar Ferreira et al. Hermenêutica e direitos fundamentais. Brasília: Brasília Jurídica, 2002, p. 125.
} 
WEISSHEIMER, Loreno. Direitos fundamentais, perspectiva histórica, características e função. Revista Eletrônica Direito e Política, Programa de Pós-Graduação Stricto Sensu em Ciência Jurídica da UNIVALI, Itajaí, v.10, n.2, $1^{\circ}$ quadrimestre de 2015. Disponível em: www.univali.br/direitoepolitica - ISSN 1980-7791.

Essa característica, na visão de Canotilho ${ }^{59}$, tem como sua principal consequência "a proteção dos direitos fundamentais perante o próprio controle jurisdicional de constitucionalidade exercido sobre os atos normativos que os regulam". É uma características que não é absoluta, pois "podem existir direitos fundamentais não constitucionalizados, sem prejuízo de serem exercidos (fundamentalidade material)" ${ }^{\prime 60}$. E, o autor termina sua explanação afirmando que "a positivação jurídico-constitucional não dissolve nem consome quer o momento de jusnaturalização quer as raízes fundamentantes dos direitos fundamentais (dignidade humana, fraternidade, igualdade, liberdade)" ${ }^{61}$.

\subsection{A Vinculação dos Poderes Públicos}

No tocante a característica de vinculação dos poderes públicos, tem-se que: "todos os poderes públicos são vinculados aos direitos fundamentais, no sentido de que não se tratam de simples programas ou carta de intenção, mas de normas revestidas de razoável efetividade". ${ }^{62}$

Essa característica aliada à sua constitucionalização, conforme leciona Sant'Ana:

[...] impede sejam eles passíveis de ser alterados ou suprimidos à simples conveniência dos poderes constituídos, na medida em que o poder que consagra os direitos fundamentais é superior. Os poderes constituídos devem agir em conformidade com os direitos fundamentais, sob

${ }^{59}$ CANOTILHO, José Joaquim Gomes. Direito constitucional. 7. ed. Coimbra: Almedina, 2002, p. 372.

${ }^{60}$ CANOTILHO, José Joaquim Gomes. Direito constitucional. 7. ed. Coimbra: Almedina, 2002, p. 373.

${ }^{61}$ CANOTILHO, José Joaquim Gomes. Direito constitucional. 7. ed. Coimbra: Almedina, 2002, p. 354.

62 SANTOS, Fernanda Barbosa dos; MARQUES, Leonardo Augusto Marinho; DUARTE Hugo Garcez. Direitos fundamentais: a busca por sua efetivação. Disponível em: <http://ambitojuridico.com.br/site/index.php?artigo_id=10201\&n_link=revista_artigos_leitura>. Acesso em mar. 2015, p.9. 
WEISSHEIMER, Loreno. Direitos fundamentais, perspectiva histórica, características e função. Revista Eletrônica Direito e Política, Programa de Pós-Graduação Stricto Sensu em Ciência Jurídica da UNIVALI, Itajaí, v.10, n.2, $1^{\circ}$ quadrimestre de 2015. Disponível em: www.univali.br/direitoepolitica - ISSN 1980-7791.

pena de invalidação de seus atos, vez que tais direitos são qualificados como obrigações indeclináveis do Estado ${ }^{63}$.

Ressalta-se que, até mesmo em situações onde o legislador está incumbido de restringir certos direitos, diante do que preceitua o texto constitucional, "deverá o elaborador da norma preservar seu núcleo essencial, ou seja, criar condições que não impossibilitem o exercício desses direitos" ${ }^{\prime 64}$.Ainda nessa vereda, o autor supra citado entende ser "do judiciário o papel mais importante na preservação dos núcleos essenciais, pois cabe a ele conferir o máximo de eficácia possível, recusando "aplicação a preceitos que não respeitem os direitos fundamentais". ${ }^{65}$

A Constituição Federal ${ }^{66}$ de 1988 , em seu art. 60, § 40, dispõe:

Art. 60. A Constituição poderá ser emendada mediante proposta:

$[\ldots]$

$\S 40$ - Não será objeto de deliberação a proposta de emenda tendente a abolir:

I - a forma federativa de Estado;

II - o voto direto, secreto, universal e periódico;

III - a separação dos Poderes;

IV - os direitos e garantias individuais (BRASIL, 1988).

Assim, a vinculação dos poderes públicos ao cumprimento dos direitos fundamentais ostenta não apenas a qualidade de princípio, mas também de norma expressa ${ }^{67}$.

${ }^{63}$ SANT'ANA, Juliana Silva Barros de Melo. Os direitos fundamentais e suas características essenciais. 2012. Disponível em: <http://www.conteudojuridico.com.br/artigo,os-direitosfundamentais-e-suas-caracteristicas-essenciais,50276.html >. Acesso em mar. 2015, p.3.

${ }^{64}$ BRANCO, Paulo Gustavo Gonet. Aspectos de teoria geral dos direitos fundamentais. In: MENDES, Gilmar Ferreira et al. Hermenêutica e direitos fundamentais. Brasília: Brasília Jurídica, 2002, p. 127.

${ }^{65}$ BRANCO, Paulo Gustavo Gonet. Aspectos de teoria geral dos direitos fundamentais. In: MENDES, Gilmar Ferreira et al. Hermenêutica e direitos fundamentais. Brasília: Brasília Jurídica, 2002, p. 132.

66 BRASIL. Constituição (1988). Constituição da República Federativa do Brasil. Brasília, DF, Senado,1998. 
WEISSHEIMER, Loreno. Direitos fundamentais, perspectiva histórica, características e função. Revista Eletrônica Direito e Política, Programa de Pós-Graduação Stricto Sensu em Ciência Jurídica da UNIVALI, Itajaí, v.10, n.2, 10 quadrimestre de 2015. Disponível em: www.univali.br/direitoepolitica - ISSN 1980-7791.

Canotilho defende a impossibilidade de retrocesso social dos direitos fundamentais:

[...] o núcleo essencial dos direitos sociais já realizado e efetivado através de medidas legislativas deve considerar-se constitucionalmente garantido, sendo inconstitucionais quaisquer medidas estaduais que, sem a criação de outros esquemas alternativos ou compensatórios, se traduzam na prática numa 'anulação', 'revogação', 'aniquilação', pura e simples desse núcleo essencial ${ }^{68}$.

Em suma, como aduz Uchôa69: "assim como legislativo, também judiciário e executivo estão vinculados ao cumprimento dos direitos fundamentais de um lado por suas atuações administrativas, e, de outro, por suas atividades específicas".

\section{FUNÇÃO DOS DIREITOS FUNDAMENTAIS}

A função dos direitos humanos fundamentais, segundo leciona Canotilho, tem:

[...] por objetivo, a efetividade do cumprimento dos direitos que os asseguram, a função de direitos de defesa dos cidadãos sob uma dupla perspectiva constituem num plano jurídico-objetivo, normas de competência negativa para os poderes públicos, proibindo fundamentalmente as ingerências destes na esfera jurídica individual; implicam, num plano jurídico subjetivo o poder de exercer positivamente direitos fundamentais (liberdade positiva) e de exigir omissões dos poderes públicos de forma a evitar agressões lesivas dos mesmos (liberdade negativa) ${ }^{70}$.

67 UCHÔA, Marcelo Ribeiro. Direitos fundamentais: noções gerais e resolução de conflitos. 2006. 55f. monografia da Universidade de Fortaleza, Curso de Mestrado em Direito Constitucional. Fortaleza. 2006, p. 20.

68 CANOTILHO, José Joaquim Gomes, apud BRANCO, Paulo Gustavo Gonet. Aspectos de teoria geral dos direitos fundamentais. In: MENDES, Gilmar Ferreira et al. Hermenêutica e direitos fundamentais. Brasília: Brasília Jurídica, 2002, p. 127.

69 UCHÔA, Marcelo Ribeiro. Direitos fundamentais: noções gerais e resolução de conflitos. 2006. 55f. monografia da Universidade de Fortaleza, Curso de Mestrado em Direito Constitucional. Fortaleza. 2006, p. 20.

70 CANOTILHO, José Joaquim Gomes, apud SANTOS, Fernanda Barbosa dos; MARQUES, Leonardo Augusto Marinho; DUARTE Hugo Garcez. Direitos fundamentais: a busca por sua efetivação. Disponível em: <http://ambito- 
WEISSHEIMER, Loreno. Direitos fundamentais, perspectiva histórica, características e função. Revista Eletrônica Direito e Política, Programa de Pós-Graduação Stricto Sensu em Ciência Jurídica da UNIVALI, Itajaí, v.10, n.2, $1^{\circ}$ quadrimestre de 2015. Disponível em: www.univali.br/direitoepolitica - ISSN 1980-7791.

Além das funções hora descritas, aponta a doutrina duas dimensões distintas de direitos fundamentais: a dimensão objetiva e a dimensão subjetiva. Conforme descrevem Santos, Marques e Duarte ${ }^{71}$.

A dimensão subjetiva caracteriza-se pelos destinatários dos direitos,ou seja o próprio homem, individualmente considerado. A dimensão subjetivamente considerada, apresenta as seguintes características: São direitos subjetivos (de fruição individual), de igualdade, universais e fundamentais. A dimensão objetiva é entendida como a garantia de gozo e participação política, em atuação positiva do Estado.

Segundo Diniz ${ }^{72}$, "o direito à vida, integrante do rol dos direitos fundamentais, é autêntico 'excludendi alios'" que determina, no mínimo, "um comportamento negativo dos entes da sociedade no sentido de não ser atacado, ferido, violado. Ademais, como condicionante dos demais direitos da personalidade, a vida deve ser protegida 'contra tudo e contra todos'"173, desde o seu início até o seu fim natural. Nesse mesmo caminho, coaduna Reis ${ }^{74}$ que, "a primeira função dos direitos fundamentais é a defesa da pessoa humana e da sua dignidade perante os poderes do Estado".

juridico.com.br/site/index.php?artigo_id=10201\&n_link=revista_artigos_leitura $>$. Acesso em mar. 2015, p.18.

71 SANTOS, Fernanda Barbosa dos; MARQUES, Leonardo Augusto Marinho; DUARTE Hugo Garcez. Direitos fundamentais: a busca por sua efetivação. Disponível em: <http://ambitojuridico.com.br/site/index.php?artigo_id=10201\&n_link=revista_artigos_leitura>. Acesso em mar. 2015, p.18.

72 DINIZ, Maria Helena. 0 estado atual do biodireito. 6. ed. rev. aum. e atual. São Paulo: Saraiva, 2009. p. 22.

73 DINIZ, Maria Helena. O estado atual do biodireito. 6. ed. rev. aum. e atual. São Paulo: Saraiva, 2009, p. 21

74 REIS, Clayton. A dignidade do nascituro. In: CORRÊA, Elídia Aparecida; GIACOIA, Gilberto; CONRADO, Marcelo (coords.). Biodireito e dignidade da pessoa humana: diálogo entre a ciência e o direito. Curitiba: Juruá, 2006, p.72. 
WEISSHEIMER, Loreno. Direitos fundamentais, perspectiva histórica, características e função. Revista Eletrônica Direito e Política, Programa de Pós-Graduação Stricto Sensu em Ciência Jurídica da UNIVALI, Itajaí, v.10, n.2, $1^{\circ}$ quadrimestre de 2015. Disponível em: www.univali.br/direitoepolitica - ISSN 1980-7791.

\subsection{Função de Defesa}

Os direitos fundamentais têm função de defesa, ou seja, segundo Santos ${ }^{75}$, "o Estado não deve interferir na esfera de liberdade do indivíduo". ${ }^{76}$

Estes direitos têm função sob uma dupla perspectiva: "a) constituem normas de competência negativa para os poderes públicos; b) o poder de exercer positivamente os direitos fundamentais e exigir dos poderes públicos as omissões destes para evitar agressões a tais direitos"777.

\subsection{Função de Prestação Social}

Os direitos fundamentais não mais se circunscrevem às limitações do Estado. Mas também à prestações positivas do poder público, conforme destaca Sarlet:

Os direitos fundamentais passaram a apresentar-se no âmbito da ordem constitucional como um conjunto de valores objetivos básicos e fins diretivos da ação positiva dos poderes públicos, e não apenas garantias negativas dos interesses individuais ${ }^{78}$.

Contudo, verifica-se as limitações do estado no atendimento aos Direitos Fundamentais. O Supremo Tribunal Federal ${ }^{79}$ discorre em sua jurisprudência as modalidades de comportamentos comissivos ou omissos do poder público:

\section{DESRESPEITO À CONSTITUIÇÃO MODALIDADES DE COMPORTAMENTOS INCONSTITUCIONAIS DO PODER}

\footnotetext{
75 SANTOS, Fernanda Barbosa dos; MARQUES, Leonardo Augusto Marinho; DUARTE Hugo Garcez. Direitos fundamentais: a busca por sua efetivação. Disponível em: <http://ambitojuridico.com.br/site/index.php?artigo_id=10201\&n_link=revista_artigos_leitura>. Acesso em mar. 2015. p. 17.

76 SANTOS, Giana Almeida dos. A eficácia das ações afirmativas em face dos direitos fundamentais. 2008. 66f. Trabalho de Conclusão de Curso de Direito da Universidade Católica de Brasília. Brasília. 2008, p. 17.

77 CANOTILHO, José Joaquim Gomes. Direito constitucional. 7. ed. Coimbra: Almedina, 2002, p. 408.

78 SARLET, Ingo Wolfgang. A eficácia dos direitos fundamentais. 6. ed. rev. atual. Porto Alegre: Livraria do Advogado, 2006, p.167.

79 REVISTA TRIMESTRAL DE JURISPRUDÊNCIA. (RTJ) 185/794-796, Ref. Min. Celso de Mello, Pleno.
} 
WEISSHEIMER, Loreno. Direitos fundamentais, perspectiva histórica, características e função. Revista Eletrônica Direito e Política, Programa de Pós-Graduação Stricto Sensu em Ciência Jurídica da UNIVALI, Itajaí, v.10, n.2, 10 quadrimestre de 2015. Disponível em: www.univali.br/direitoepolitica - ISSN 1980-7791.

PÚBLICO. - O desrespeito à Constituição - O desrespeito à Constituição tanto pode ocorrer mediante ação estatal quanto mediante inércia governamental. A situação de inconstitucionalidade pode derivar de um comportamento ativo do Poder Público, que age ou edita normas em desacordo com o que dispõe a Constituição, ofendendo-lhe, assim, os preceitos e os princípios que nela se acham consignados. Essa conduta estatal, que importa em um facere (atuação positiva), gera a inconstitucionalidade por ação. - Se o Estado deixar de adotar as medidas necessárias à realização concreta dos preceitos da Constituição, em ordem a torná-los efetivos, operantes e exeqüíveis, abstendo-se, em conseqüência, de cumprir o dever de prestação que a Constituição Ihe impôs, incidirá em violação negativa do texto constitucional. Desse non facere ou non praestare, resultará a inconstitucionalidade por omissão, que pode ser total, quando é nenhuma a providência adotada, ou parcial, quando é insuficiente a medida efetivada pelo Poder Público. - A - A omissão do Estado - que deixa de cumprir, em maior ou em menor extensão, a imposição ditada pelo texto constitucional - qualifica-se como comportamento revestido da maior gravidade político-jurídica, eis que, mediante inércia, o Poder Público também desrespeita a Constituição, também ofende direitos que nela se fundam e também impede por ausência de medidas concretizadoras, a própria aplicabilidade dos postulados e princípios da Lei Fundamental. (RTJ 185/794-796, Rel. Min. CELSO DE MELLO, Pleno).

\subsection{Função de Não-Discriminação}

A função de não discriminação tem como embasamento o princípio da igualdade, sendo este, o elemento substancial e primeiro de todos os direitos fundamentais. O mesmo deve ser "aplicado tanto nos direitos individuais quanto nos direitos de coletividade. É sob este fundamento que se discute o grande problema das cotas e das ações afirmativas" ${ }^{80}$.

Ao se fazer menção a Corte Europeia dos direitos do homem e do cidadão, verifica-se que esta definiu como discriminação não autorizada "aquela que não tenha uma justificação objetiva ou razoável. Seria somente permitida

${ }^{80}$ CANOTILHO, José Joaquim Gomes. Direito constitucional. 7. ed. Coimbra: Almedina, 2002, p. 410. 
WEISSHEIMER, Loreno. Direitos fundamentais, perspectiva histórica, características e função. Revista Eletrônica Direito e Política, Programa de Pós-Graduação Stricto Sensu em Ciência Jurídica da UNIVALI, Itajaí, v.10, n.2, $1^{\circ}$ quadrimestre de 2015. Disponível em: www.univali.br/direitoepolitica - ISSN 1980-7791.

discriminação quando se tem um fim legítimo e existe uma relação razoável de proporcionalidade entre os meios e os fins" ${ }^{81}$.

Também há discriminação quando "um indivíduo ou um grupo, sem justificação adequada, se vê menos bem tratado que outro, mesmo quando o texto da Convenção não imponha o tratamento mais favorável" ${ }^{82}$.

\section{CONSIDERAÇÕES FINAIS}

Mediante a pesquisa levantada sobre o tema, verificou-se que os direitos fundamentais perfilhados ao ser humano não dependem da capacidade, do caráter ou da preferência individual, mesmo sendo de caráter religioso, ideológico, partidário, sexual, ou qualquer outra espécie; mas sim, são frutos de uma longa evolução histórica, surgindo aos poucos até consolidarem-se consensualmente.

Os direitos humanos são culturais, sendo que a sua significação em conteúdo se apresenta cada vez mais crescente, à medida que a própria humanidade evolui se depara com novas tecnologias e conhecimentos, surgindo assim novos direitos primordiais à pessoa humana.

O Moderno Estado de Direito fundamenta-se numa Lei Fundamental, que, além de ser proclamada por uma ação democrática, também tenha supremacia e permeie organismos de controle dos Poderes. Além destes requisitos, as Constituições contemporâneas assinalam significativa importância frente à variada enumeração e eficácia dos direitos e garantias fundamentais.

${ }^{81}$ SANTOS, Fernanda Barbosa dos; MARQUES, Leonardo Augusto Marinho; DUARTE Hugo Garcez. Direitos fundamentais: a busca por sua efetivação. Disponível em: <http://ambitojuridico.com.br/site/index.php?artigo_id=10201\&n_link=revista_artigos_leitura>. Acesso em mar. 2015, p.18.

82 PASSOS, José Joaquim Calmon de. O principio da não discriminação. 2007. Disponível em: $<$ http://www.direitodoestado.com/revista/RERE-11-SETEMBRO-2007-

CALMON\%20DE\%20PASSOS.pdf>. Acessado em mar. 2015, p. 7. 
WEISSHEIMER, Loreno. Direitos fundamentais, perspectiva histórica, características e função. Revista Eletrônica Direito e Política, Programa de Pós-Graduação Stricto Sensu em Ciência Jurídica da UNIVALI, Itajaí, v.10, n.2, $1^{\circ}$ quadrimestre de 2015. Disponível em: www.univali.br/direitoepolitica - ISSN 1980-7791.

\section{REFERÊNCIA DAS FONTES CITADAS}

AMARAL, Renata Campetti. O direito internacional: público e privado. 4. ed. Porto Alegre: Verbo Jurídico, 2008.

ANTUNES, Ruy Barbedo. Direitos Fundamentais e Direitos Humanos: a questão relacional. Rev. Esc. Direito, Pelotas, v. 6, n. 1, p. 331-356, jan./dez., 2005.

BARROSO, Luís Roberto. A Dignidade da Pessoa Humana no Direito Constitucional Contemporâneo, A Construção de um Conceito Jurídico à Luz da Jurisprudência Mundial, editora Fórum, 2.a reimpressão, Belo Horizonte, 2013.

BRANCO, Paulo Gustavo Gonet. Aspectos de teoria geral dos direitos fundamentais. In: MENDES, Gilmar Ferreira et al. Hermenêutica e direitos fundamentais. Brasília: Brasília Jurídica, 2002.

COMPARATO, Fábio Konder. A afirmação histórica dos direitos humanos. 3. ed. São Paulo: Saraiva, 2003.

CANOTILHO, José Joaquim Gomes.Direito constitucional e teoria da constituição. 3. ed. Coimbra: Almedina, 1998.

Direito constitucional. 7. ed. Coimbra: Almedina, 2002.

D'ANGELIS, Wagner Rocha, (Org.). Direito internacional do século XXI: integração, justiça e paz. Curitiba: Juruá, 2007.

DINIZ, Maria Helena. O estado atual do biodireito. 6. ed. rev. aum. e atual. São Paulo: Saraiva, 2009.

FIORAVANTI, Maurizio. Los derechos fundamentales. 4. ed. Madrid: Trotta, 2003.

GARCIA, Marcos Leite. A Contribuição de Christian Thomasius ao Processo de Formação do Ideal dos Direitos Fundamentais. In.: Novos Estudos Jurídicos v. 10 - n. ${ }^{2}$ - p. 417 jul/dez - 2005, 
WEISSHEIMER, Loreno. Direitos fundamentais, perspectiva histórica, características e função. Revista Eletrônica Direito e Política, Programa de Pós-Graduação Stricto Sensu em Ciência Jurídica da UNIVALI, Itajaí, v.10, n.2, $1^{\circ}$ quadrimestre de 2015. Disponível em: www.univali.br/direitoepolitica - ISSN 1980-7791.

ISRAEL, Jean-Jacques. Direito das liberdades fundamentais. Barueri: Manole, 2005.

JO, Hee Moon. Introdução ao direito internacional. 2. ed. São Paulo: LTr, 2004.

LUÑO, Antonio Enrique Pérez. Derechos humanos, estado de derecho y constitucion.6. ed. Madrid: Tecnos, 1999.

MAIA, Bruna Michelle Pereira. Tratados internacionais de direitos humanos no ordenamento jurídico brasileiro. 2014. 36f. Trabalho de Conclusão de Curso de Direito da Faculdade de Ciências Jurídicas da Universidade Tuiuti do Paraná. Curitiba. 2014.

MIRANDA, Jorge. Manual de direito constitucional Tomo IV. 3. ed. Coimbra: Coimbra, 2000

PASOLD, Cesar Luis. Metodologia da pesquisa jurídica: Teoria e prática. 11 ed. Florianópolis: Conceito Editorial/Milleniuum, 2008.

PASSOS, José Joaquim Calmon de. O principio da não discriminação. 2007. Disponível em: <http://www.direitodoestado.com/revista/RERE-11-SETEMBRO2007-CALMON\%20DE\%20PASSOS.pdf>. Acessado em mar. 2015.

PECES-BARBA, Gregório. Curso de Derechos Fundamentales: teoria general. Madrid: Universidad Carlos III, 1995.

PIOVESAN, Flávia. Direitos humanos e o direito constitucional internacional. São Paulo: Max Limonad, 2002.

REIS, Clayton. A dignidade do nascituro. In: CORRÊA, Elídia Aparecida; GIACOIA, Gilberto; CONRADO, Marcelo (coords.). Biodireito e dignidade da pessoa humana: diálogo entre a ciência e o direito. Curitiba: Juruá, 2006.

REVISTA TRIMESTRAL DE JURISPRUDÊNCIA. (RTJ) 185/794-796, Ref. Min. Celso de Mello, Pleno. 
WEISSHEIMER, Loreno. Direitos fundamentais, perspectiva histórica, características e função. Revista Eletrônica Direito e Política, Programa de Pós-Graduação Stricto Sensu em Ciência Jurídica da UNIVALI, Itajaí, v.10, n.2, $1^{\circ}$ quadrimestre de 2015. Disponível em: www.univali.br/direitoepolitica - ISSN 1980-7791.

SANT'ANA, Juliana Silva Barros de Melo. Os direitos fundamentais e suas características $2012 . \quad$ essenciais. Disponível em: <http://www.conteudojuridico.com.br/artigo,os-direitos-fundamentais-esuas-caracteristicas-essenciais,50276.html>. Acesso em mar. 2015.

SANTOS, Fernanda Barbosa dos; MARQUES, Leonardo Augusto Marinho; DUARTE Hugo Garcez. Direitos fundamentais: a busca por sua efetivação. Disponível em:<http://ambito-juridico.com.br/site/index.php?artigo $\quad$ id=10201\&n _link=revista_artigos_leitura >. Acesso em mar. 2015.

SANTOS, Giana Almeida dos. A eficácia das ações afirmativas em face dos direitos fundamentais. 2008. 66f. Trabalho de Conclusão de Curso de Direito da Universidade Católica de Brasília. Brasília. 2008.

SARLET, Ingo Wolfgang. A eficácia dos direitos fundamentais. 6. ed. rev. atual. Porto Alegre: Livraria do Advogado, 2006.

SILVA, José Afonso da. Curso de Direito Constitucional Positivo. 32a.ed, Malheiros, São Paulo: 2009.

SIQUEIRA, Dirceu Pereira; PICCIRILLO, Miguel Belinati. Direitos fundamentais: a evolução histórica dos direitos humanos, um longo caminho. In: Âmbito Jurídico, Rio Grande, XII, n. 61, fev 2009.

UCHÔA, Marcelo Ribeiro. Direitos fundamentais: noções gerais e resolução de conflitos. 2006. 55f. monografia da Universidade de Fortaleza, Curso de Mestrado em Direito Constitucional. Fortaleza. 2006.

WEYNE, Bruno Cunha. O Princípio da Dignidade Humana, Reflexões a partir da filosofia de Kant, Editora Saraiva, São Paulo, 2013.

Submetido em: Março/2015

Aprovado em: Abril/2015 